Volume 8

Issue 2 July

Article 11

July 1981

\title{
Like Other Women: Perspectives of Mothers with Physical Disabilities
}

\author{
Susan Shaul \\ Elliott Bay Health Associates \\ Pamela Dowling \\ Elliott Bay Health Associates \\ Bernice F. Laden \\ Elliott Bay Health Associates
}

Follow this and additional works at: https://scholarworks.wmich.edu/jssw

Part of the Family, Life Course, and Society Commons, Gender and Sexuality Commons, and the Social Work Commons

\section{Recommended Citation}

Shaul, Susan; Dowling, Pamela; and Laden, Bernice F. (1981) "Like Other Women: Perspectives of Mothers with Physical Disabilities," The Journal of Sociology \& Social Welfare: Vol. 8 : Iss. 2 , Article 11.

Available at: https://scholarworks.wmich.edu/jssw/vol8/iss2/11 
LIKE OIHER WOMEN: PERSPECIIVES OF MOTHERS WITH PHYSICAL DISABIITTIES

Susan Shaul, Ph.D.

Elliott Bay Health Associates

Pamela Dowling

Elliott Bay Health Associates

Bernice F. Laden, B.S.

Elliott Bay Health Associates

\section{ABSTRACT}

This article is based on interviews with ten wamen, ranging in age from 19 to 45 and living in the Puget Sound area of Washington State. Their disabilities are neurcmuscular or musculoskeletal and include spinal cord injury, multiple sclerosis, post-polio and spina bifida. Their children range in age from 11 months to adulthood. The article focuses on specific issues and concerns regarding early childhood management, and includes some discussion of pre-natal and obstetrical care. Cammon misconceptions concerning motherhood and disability are also discussed. Men with disabilities also have apecial concerns as parents. Although their concerns are not addressed in this paper, they are not seen as any less important or deserving of attention. Work on this paper was made possible under Grant \#10H53008032 fram the Department of Health and Human Services, Bureau of Camminity Health Services, Family Planning Program, 1980.

Until recently there has been a cultural bias that wamen with disabilities cannot and should not bear and raise children. Consequently, family planning services, obstetrical care and early childhood management have often neglected the needs of women with disabilities. Mainstreaming, implementation of section 503 and 504 of the national Rehabilitation Act of 1973, and other new state and federal legislation have begun to have an impact on service delivery to the disabled population, providing greater opportunities and increasingly complex choices. While many disabled wamen choose to pursue careers, others want to direct their energies toward raising children, or combining career and family. However, society's attitude toward wamen with disabilities has been slow to change. 
This resistance has been reflected in the lack of literature available to parents with disabilities. May (1974) discusses minor architectural adaptations and recreational activities mothers with physical disabilities might accamplish. Otherwise, American society as reflected in the literature, has denied any special needs. This denial reflects the larger attitudinal barriers faced by people with disabilities.

The stigma of being disabled is difficult to erase. A disabled woman's capacity to be a partner in an intimate, sexual relationship and her physical ability to conceive and bear a child may be doubted by even her own family. Bogle and Shaul (1979) point out, "Many congenitally disabled wamen report that their parents programmed them to be 'super career' wamen in the belief that they would never be considered marriage material." (p. 39)

Societal resistance to viewing women with disabilities as potential parents cames from several different pervasive cultural myths:

1. Physically disabled women are extraorainarily dependent on other peopte. Many nondisabled people mistakenly assume that individuals with disabilities are unable to do basic maintenance for thenselves, let alone a child. In reality, most physically disabled people lead independent, productive lives.

2. Physical disability is somehow contagious or genetically passed on. This is a remant of the belief that people with disabilities are sick or unhealthy. Only a small percentage of disabilities are genetically based.

3. Physically disabled people are asexual. Many nondisabled people often view sex as an acrobatic activity. This causes difficulty in understanding that physically disabled people are capable of enjoying warm, intimate relationships and being sexually active.

4. Being disabled is such a depressing and dreary existence that a disabled individual should not bring a child into that world. Few disabled people spend time dwelling on their disability. They are involved in working, homemaking, and the same activities that the general population enjoys.

5. Physical mobility is essential to child-rearing. Because disabled women have not been portrayed as mothers, it is difficult for the general population to understand how a child can be raised by a wamen with mobility restrictions. 
This study was therefore undertaker, as a pilot project to investigate the needs of mothers with disabilities. Ten women ir the Seattle area agreed to be interviewed. They were contacted through a previous research project (Shaul, et. al, 1978) and informal networking in the conmunity. The women had chosen to became parents after they were disabled. Their disabilities included spinal cord injury, multiple sclerosis, post-polio and spina bifida. At the time of the interviews, their children ranged in age from 11 months to mici-30's. While clearly not representative of all women with disabilities who choose to become pregnant, these wamen were able to indicate potential areas of concern and needs fram service providers.

\section{FRE PREGNANCY}

In deciding whether or not to become pregnant, most women with disabilities want to speak with a woman who has a similar disability. Many able-bodied women have relied on their mothers or friends to share what pregnancy and child-rearing are like, but disabled women of ten need more information and advice that is related to their specific disability.

I really wanted to talk to another disabled woman who had gone throuch a pregnancy to find out what sort of things to anticipate during my pregnancy and after the baby was born . . . I couldn't find anyone... I think that networking among disabled women is just now beginning to grow. (paraplegic)

There are legitimate concerns as to how the physical stress of pregnancy may affect a disabled waman. For example, mobility, respiration, or elimination, perhaps not working at "normal" levels will have the extra burden of the developing fetus.

At this point, many of these questions can be answered only by conjecture, as pregnant women with specific disabilities have not beer. studied. Health care professionals are not able to provide women with consistent answers. A woman with spina bifida told us:

I talked to my docotor about becoming pregnant and he said absolutely not; so I talked to an obstetricion and he said I should have no problems. Confused, I talked to a third docotor and he told me I should get onother opinion.

With expanded research, there will be increased professional awareness in the future, avoiding scenes that are still too cormon: 
The nurse looked at me, amazed. She said laughing, "I guess I was just surprised you were really here for a pregnancy test." (quadriplegic)

Given the wide variety of attitudes found among health care providers, and inadequate information on pregnancy and disability, what are the experiences of mothers with disabilities really like?

\section{PREGNANCY, LABOR AND DETLTVERY}

It is camton for health providers to expect that pregnancy, being a somewhat disabling condition for many nondisabled women, will cause tremendous inconvenience for disabled women. Many of the wamen in our study had very few problems with mobility and self-care. One post-polio wornan in our study, who is paraplegic and uses a wheelchair, worked until two weeks before her delivery; a woman with spina bifida stayed ambulatory (using crutches) until the delivery. Another waman (postpolio) who uses a wheelchair told us:

As I got bigger and bigger, it become harder to get up on my knees to get my pants up . . . so I just started wearing long dresses and no underwear.

Experiences with labor and delivery were similar to those of nondisabled women. One of the ten had a premature infant, two had been delivered by cassarean section, and the others had relatively uncomplicated vaginal deliveries. The three complications mentioned related specifically to the pregnancy, rather than to the womens' disabilities.

The women interviewed found the support systems available to nondisabled expectant and newly delivered wamen valuable. For example, one woman with spina bifida benefited enormously from Lamaze classes. The woman who had a premature baby participated in a neonatal intensive care unit parents' support group.

\section{PATY YEARS}

One of the most difficult times for child management is the first few years of the child's life. During this time, physically caring for the baby or young child usually requires some environmental modifications. The mothers found little commercially available. One woman said that pre- asd post-natally she had a physical therapist, social worker, and interested nursing student all looking for different mecharical aids to ease child care. They came back empty-handed. 
Over time, each woman found various devices to ease transporting her child. For one woman with spina bifida it was an "Ombroller", a lightweight stroller that is easily collapsible and portable.

The Umbrolier was helpful because the baby doesn't have to be able to sit up. I'd walk a step, take my hand coway from the crutch, push the strolier down the hall a few feet, walk a few more steps and push it a little further.

Another waman's father came up with same physical modifications:

My dad built a tray that snapped onto the arms of my wheelchair. The baby could be inside the tray and my arms would be free to push my chair. I also used a portable bassinet with wheels that allowed me to push the baby from room to room. For a chonging table, we took the short legs off an old coffee table and replaced them with long legs that raised the baby to just the right height. (paraplegic)

Going out alone is scmewhat difficult for many new mothers, but it is aggravated by the encumbrances of disability. For a woman who uses a wheelchair, an infant can mark a temporary end to being able to travel around independently. It is difficult to push a wheelchair around shopping centers and hold onto an active child in your lap at the same time. out.

Getting a baby in and out of a car can be a major obstacle to going

The biggest restriction I found during that time was the difficulty in taking him somewhere by myself. I have been driving sinue I was 26 and it was the first time my driving . . . independence had been restricted. I enter the car on the passenger side and slide over to the driver's seat. It was difficult to manage baby, car seat and wheelchair. So until he learned to walk, I usually had a family member or friend accompany us on our outings. (paraplegic) 
It is likely too, that daily child management requires more energy fram disabled women, which can lead to exhaustion. This period seemed to end for the women when relieved of a share of the responsibility. For one family in our study, the pediatrician recommended a "24-hour break for Mam, once a week," when the child would go to his grandparents. In other families, it was pre-school that enabled the mother to think about her own goals again, contact friends, and rebuild intimacy with her husband. All of the husbands had provided significant help with household chores, as well as child management. Several worked evenings, giving a handy break to the mothers during the day by helping out with dinner, dishes, calming temper tantrums and organizing playtime activities.

\section{DISCIPLINE}

In the area of discipline, the families had adapted to the "givens" in the situation and had found ingenious solutions. Primary for everyone was the understanding that verbal commands are law. This was not always easy to do, but families had various ways of enforcing verbal authority.

I depend a lot on voice control. She has to come to my commands. I can't pick her up every time she falls because maybe the chair isn't positioned right. Once she fell off her trike on the romp and there was no way I could come out and get her untangled. She realized that and got herself untangled. She's just more cware of voice control. She has to be able to understand. (woman with multiple sclerosis)

One waman said that the best advice she had received was from her pediatrician, who recormended that she only make demands that she could enforce and be much more selective about what she was demanding of the child.

Developing authority behind verbal cammands is often difficult for the parent with a disability because of the internittent reinforcement of limit-testing with the nondisabled parent or other nondisabled people. For instance, one mother had very few discipline problems until her daughter went to a pre-school where the teachers were very physical in restraining the children and often did things for the little girl she was capable of doing herself. Similarly, relatives or other interested people would pick her up when she was misbehaving. Then she came hame and started testing already detemined limits. 
I'd say to my friends, "I have to rely on voice commands and when you walk over and do sometring for her or pick her up, you're really putting a crunch on me, because then she expects me to do it." (quadriplegic)

The choice is made very early whether to keep the child confined within reach (which none of the parents had chosen) or give the child reasonable freedom while trusting in their survival skills. The children's adaptive capabilities are dramatic: they learn to climb on Man's lap when hurt, reach up to be lifted out of a crib, or hold onto a wheelchair when crossing the street as if it were Mam's hand.

I emphasized early how important it was to listen to what I said because there would be times I might not be able to get to him to help him out of a jam. Be seemed to understand that. Be is very good at listening to me about not going into the street, straying cway in stores, or going someplace I may not be able to get to. But when it comes time for dinner, bedtime, or bath, he is like any other child and heads in the opposite direction! (paraplegic)

Some problems were eased by environmental revisions. Homes with disabled adults often have fewer pieces of furniture, as they restrict mobility. This cuts down on the number of obstacles for a toddler. Traditional environmental revisions included safety plugs in sockets, glassware put away, dead-bolt locks (so the child couldn't get in and out to the street inciependently), fenced-in yards, and other todd.'er proofing mechanisms.

As mentioned earlier, child-rearing is far fram a fait accompli for the able-bodied population. All mothers have questions regarding appropriate discipline techniques.

You have to remind yourself that your disability really has nothing to do with whatever the problem is at hand . . you know, it's a parent-child thing, not a disabled parent-child thing. (woman with multiple sclerosis)

Unfortunately, wamer with disabilities are placed in a double-bind. on the one hand they are told "you couldn't possibly raise children and discipline them well," and on the other, when everything turns out all 
right, they hear, "Well, dear, your child had to be good."

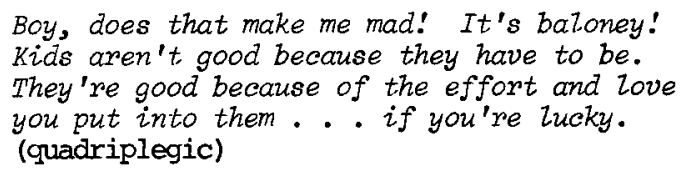

\section{ADVANTAGES AND DISADVANTAGES}

At one point during the interview, we asked each woman, "Can you think of any advantages to being a disabled parent?" Most stressed that their children had an increased sense of independence because the child knew that same things wouldn't be done for him/her. Mothers mentioned that their children were getting dressed by themselves earlier, learning about keys and locks, getting food for themselves, and genuinely being helpful before their peers in nondisabled households. Most were concerned that this not be too oppressive:

I don't like kids to have to help their parents because of their disability. I don't want him waiting on me. I don't need that. I don't want him to think he has to do that for me. (woman with spira bifida)

Disability was often the stimulus to encourage independence in children for philosophical, as well as practical reasons:
We were always very strict with the kids. We thought, "What if something happened to my husband or maybe we'd both die!" The polio brought i.t closer to you that you might die, so we tried to get the kids to be very responsible for themselves, and I think they were quite adult for their ages. (paraplegic)

Another advantage that the women cited was their children's increased sensitivity to other stigmatized individuals. Sometimes this took the form of defending or befriending "picked-on" children who were classmates, or not caring if someone "looked a little different." Most of the mothers had had the experience of being "defended" by their child to the world at large:

One time we were ir a cafeteria-type place and this woman kept staring and staring at me. 


\begin{abstract}
Finally, my dougher (aged 20) needed to walk by this stronger and my doughter said, "you know, it's not nice to stare!" When she told me, I said, "You didn't,'" and she said, "I sure did!" and we laughed and laughed. (quadriplegic)
\end{abstract}

The wamen were also able to cite same disadvantages to being disabled and a parent. The most significant disadvantage seemed to be various family acitvities that were difficult or impossible to participate in. One mother talked about not being able to attend a school play one of her children was in because the school was not accessible and she couldn't find any help that day. For a quadriplegic woman, there was the sadness of not. being able to teach her daughter how to use scissors or a hammer. One of the paraplegic women said, "How can I teach him how to play hopscotch or swim?" Most of the mothers acknowledged other people are available to help with these activities (father, grandparents, friends, aunts or uncles), but that they nonetheless feel a sense of loss.

Extended absences from their children because of medical needs were also disadvantages. This varies with the nature of the disability, being more of a concern with progressive disabilities.

My daughter is constantly afriad I'm going to leave her and go back to the hospital for some complication or another of the multiple sclerosis. (woman with multiple sclerosis)

For those woman injured after their children are already born, there is often a long readjustment period when they re-enter the home-a readjustment to Mom being back and then another to her being "different."

As children of mothers with disabilities came into contact with their peers, there may be an initial tension with the other children from having a mother who is different. One waman related an incident where her first-grader came home in tears. When he was able to tell her what had happened, he told her that he didn't want her to come to school anymore because all the kids made fun of the way she walked and he was the only kid with a Mom who was "different." After canforting him, she spoke to his teacher and made arrangements to come to school and do a little "inservice" with the kids, allowing them to ask questions and get to know her as Joey's Mam, instead of only as the "waman who walks funny." 


\section{RECOMMENDATIONS}

Through this survey of wamen, many unmet needs became obvious. The following recammendations are based on concerns expressed by women with disabilities.

Pre-pregnancy counseling. Campiling experiences of mothers who are disabled and making the information available would be beneficial to wamen with disabilities contemplating motherhood. Peer groups or individual peer counselors could be made available for disabled women.

Human service professionals need additional training in the area of disability and pregnancy so they will be better equipped to answer questions posed by disabled wamen. Institutions of higher education and health care education programs could inoorporate a module on sexuality, pregnancy and disability. Perhaps having a disabled mother visit classes to share experiences would be helpful to potential health care providers

Prenatal/obstetrical care. More training and information on pregnancy and disability needs to be available in medical school curriculum so there will be more physicians available to give obstetrical care to women with disabilities in a comfortable and knowledgeable manner. Lamaze and other childbirth preparation classes should be held in accessible meeting places and made available to disabled women.

Child management. Resource listings of adaptive devices or suggestions which would make child management easier should be developed and updated in a central clearinghouse. A support group of disabled mothers would foster sharing resources.

Research. Too mach of the areas of female sexuality, reproduction, and parenting, at this point is conjecture. Further research on medical implications of pregnancy and social inplications of disabled parents is needed.

The technology of rehabilitation needs to catch up with the technology of abstetrics. There must be ways to make child care easier for disabled parents. As one waman said, "They invented the weelchair, surely they can invent an attachment to transport a child." Such "convenience" devices would have a tremendous positive impact for parents with disabilities. 
The traditional role of women as mothers is one of sole caretaker and nurturer of her children (i.e. feeding, dressing, chauffering, nursing, and disciplining). Although this image is in the process of change, it is still one which society uses as its reference point. Since disabled persons are often seen as "sick," and in need of being taken care of, it is difficult for society to understand how a mother with a disability can fit the active nurturer/caretaker role. The majority of people have a hard time imagining how people with disabilities function and take care of themselves, let alone their children. As more and more disabled people enter the mainstream of life through employment, recreation, education and mediz representation, the myths surrounding disability will begin to lessen.

The strengths and capabilities of the women we spoke with were striking. They, like able-bodied parents, felt that children dramatically change one's life and that frustrations can result. They more often experienced limitations as to how much they could participate in their children's activities. But, like most parents, they said they were glad children were part of their lives.

As society's role model for mothers changes, women in general are finding more parenting and support system options available to them (i. el shared responsibility for child-rearing with partner or extended family, daycare centers, single parenting). Not only does the disabled mother benefit fran these options, but she has a wealth of information and expertise to add to the spectrum of parenting. Although there are unique concerns that merit special attention for mothers with disabilities, once these concerns are successfully addressed, more wamen with disabilities will be able to enjoy the option of motherhood. As one wamen reflected:

You don't need a body that is physically "perfect" to be a good mother. . . environments need to be modified and support systems worked out, but the most important qualification for parenting has nothing to do with physical perfection. It has to do to do with love, warmth and a willingness to share that with a child. It has to do with being haman and that is something we all shome. 


\section{REFERENCES}

Bogle, J. and S. Shaul. "Still a Woman, Still a Man," Journal of Current Social Issues, Spring, 1979, pp. 39-41.

Goffman, E. Sitgma: Notes on the Management of Spoiled Identity, Prentice Hall, New Jersey, 1963.

May, E.E., Neva R. Waggoner, Eleanor Boettke. Independent Living for the Handicapped and the Elderly, Houghton Mifflin Campany, Boston, 1974.

Shaul, S., J. Bogle, A. Norman and J. Hale-Harbaugh. Toward Intimacy: Family Planning and Sexuality Concerns of Physically Disabled wamen, Huarm Sciences Press, New York, 1978. 
These additional articles were added to this issue subsequent to the completion of this special issue and in order to fill out the approximate 225 pages per issue.

Norman Goroff

Managing Editor and Fublisher 
